\title{
Pengaruh Grit dan Kepuasan Kerja terhadap Intensi Job Hopping pada Karyawan Generasi Milenial
}

\author{
BERTHA PERMATASARI \& FAJRIANTHI* \\ Departmen Psikologi Industri dan Organisasi, Fakultas Psikologi Universitas Airlangga
}

\begin{abstract}
ABSTRAK
Penelitian ini memiliki tujuan untuk mengetahui pengaruh grit dan kepuasan kerja terhadap intensi job hopping pada karyawan generasi milenial. Penelitian ini dilakukan kepada 82 karyawan generasi milenial yang bekerja full-time dengan durasi kerja kurang dari dua tahun pada suatu perusahaan yang terdiri dari 47 laki-laki dan 35 perempuan. Alat ukur dalam penelitian ini menggunakan job hopping intention scale (JHI) 4 item, skala grit terdiri dari 12 item, dan skala kepuasan kerja terdiri dari 6 item. Setelahnya, data dianalisis menggunakan program software IBM SPSS 23.0 for MacBook melalui uji regresi linear sederhana dan linear berganda. Hasil regresi ini menunjukan bahwa grit memiliki pengaruh negatif dan signifikan terhadap intensi job hopping $(0,004<0,05)$. Selanjutnya kepuasan kerja memiliki pengaruh negatif yang signifikan terhadap intensi job hopping $(0,001<0,05)$. Grit dan kepuasan kerja secara simultan berpengaruh terhadap intensi job hopping pada karyawan generasi milenial.
\end{abstract}

Kata kunci: grit, intensi job hopping, karyawan generasi milenial, kepuasan kerja

\begin{abstract}
This study aims to determine the effect of grit and job satisfaction on intentions job hopping for millennial generation employees. This research was conducted on 82 millennial generation employees who work full-time with a working duration of less than two years at a company consisting of 47 men and 35 women. The measuring instrument in this study uses a job-hopping intention scale (JHI) of 4 items, the grit scale contains 12 items, and the job satisfaction scale consists of 6 items. After that, the data were analyzed using the program IBM SPSS 23.0 for MacBook software through simple linear and multiple linear regression tests. The regression results show that grit has a negative and significant effect on intentions job hopping $(0.004<0.05)$. Furthermore, job satisfaction has a significant negative effect on intention job hopping $(0.001<0.05)$. Grit and job satisfaction simultaneously affect intentions job hopping for millennial generation employees.
\end{abstract}

Keywords: grit, intention job hopping, job satisfaction, millennial generation employees

Buletin Penelitian Psikologi dan Kesehatan Mental (BRPKM), 2021, Vol. 1(1), 162-171

*Alamat korespondensi: Fakultas Psikologi Universitas Airlangga, Kampus B Universitas Airlangga Jalan

Airlangga 4-6 Surabaya 60286. Surel: fajrianthi@psikologi.unair.ac.id

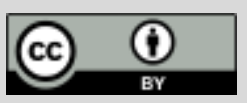

Naskah ini merupakan naskah dengan akses terbuka dibawah ketentuan the Creative Common Attribution License (CC-BY-4.0) (http://creativecommons.org/licenses/by/4.0), sehingga penggunaan, distribusi, reproduksi dalam media apapun atas artikel ini tidak dibatasi, selama sumber aslinya disitir dengan baik. 


\section{P E N D A H U L U A N}

Fenomena job hopping atau yang lebih umumnya disebut sebagai fenomena berpindah-pindah pekerjaan ini sudah menjadi isu penting dalam dunia kerja sejak lama. Job hopping merupakan suatu pola berganti-ganti perusahaan dalam kurun waktu berkerja satu atau dua tahun dengan kemauan pribadi pekerja tanpa adanya paksaan sebagai efek dari PHK atau penutupan perusahaan (Pranaya, 2014). Individu yang melakukan job hopping disebut sebagai job hopper (Larasati \& Aryanto, 2019). Job hopping sangat marak dilakukan oleh karyawan-karyawan muda dan biasanya terjadi pada generasi milenial, sehingga pada umumnya masyarakat lebih mengidentikan job hopping sebagai kebiasaan generasi milenial.

Perilaku job hopping ini dapat terjadi dibelahan dunia manapun, bukan hanya di Indonesia. Di Indonesia sendiri, survei mengenai job hopping juga sudah sering dilakukan, salah satunya yang dilakukan oleh PT. Unilever Indonesia pada tahun 2013 ini, yang menghasilkan data bahwa 60\% generasi dewasa muda di Indonesia sudah berpindah pekerjaan dalam kurun waktu tiga tahun. Bahkan sepertiga dari karyawan tersebut sudah berpindah pekerjaan sebanyak dua kali atau lebih (Ngantung, 2013).

Hasil dari berbagai survei internasional maupun nasional menunjukan bahwa kecenderungan job hopping lebih tinggi dilakukan di kalangan generasi milenial atau generasi muda. Generasi milenial merupakan sebutan untuk individu yang terlahir antara tahun 1980-2000 (Smith \& Nichols, 2015). Kaifi dkk (2012) menjelaskan bahwa generasi milenial memiliki kedekatan dengan era milenium dan mereka juga dibesarkan di jaman yang lebih digital. Generasi milenial pada umumnya memiliki kepercayaan diri yang tinggi. Kepercayaan diri itu datang dari kepercayaan dan optimisme mereka (Smith \& Nichols, 2015). Karakteristik lain dari generasi milenial adalah bahwa mereka tidak keberatan berpindahpindah pekerjaan dan kemungkinan besar tidak akan tinggal di perusahaan selama lebih dari dua tahun (Yuen, 2016). Beberapa peneliti juga melakukan penelitian yang menunjukan bahwa generasi milenial di Jerman tidak segan untuk berpindah pekerjaan, mereka lebih mementingkan nilai ekstrinsik seperti uang dan citra, sementara nilai intrinsik seperti kedekatan pada komunitas kurang penting bagi mereka. Sehingga saat nilai ekstrinsik yang mereka harapkan tidak terpenuhi, maka mereka tidak segan untuk meninggalkan perusahaannya (Yuen, 2016).

Selain faktor eksternal atau ekstrinsik seperti gaji, terdapat pula faktor internal yang harus dilihat agar dapat memahami job hopping secara menyeluruh. Yuliawan dan Himam menyatakan bahwa dalam memahami job hopping, tidak seharusnya hanya melihat satu faktor saja, melainkan dua faktor sekaligus, yaitu konten dan konteks (Sandra, 2019). Konten sendiri diartikan sebagai faktor internal dari diri seseorang yang dapat menjadi pemicu munculnya perilaku berpindah-pindah pekerjaan pada karyawan. Disisi lain, konteks merujuk pada suatu faktor pendukung yang berasal dari sekitar individu atau lingkungan sosial karyawan yang menjadi pemicu terjadinya perilaku berpindah-pindah pekerjaan pada karyawan, contohnya seperti pemasukan, organizational support, atau pekerjaan itu sendiri. Salah satu konten atau faktor internal yang sekiranya dapat digunakan untuk memahami intensi job hopping ialah grit. Pernyataan tersebut juga didukung oleh suatu penelitian yang pernah dilakukan oleh Duckworth, dkk (2007) yang mana penelitian tersebut menemukan bahwa grit menjadi satu dari sekian banyak faktor penyebab dari karyawan berpindah-pindah pekerjaan.

Sehingga, penelitian ini bertujuan untuk melihat pengaruh grit dan kepuasan kerja terhadap intensi job hopping yang terjadi pada karyawan kalangan generasi milenial. Mengingat bahwa karyawan yang masuk dalam suatu organisasi atau perusahaan akan terlebih dahulu berekspetasi tinggi terhadap upah, 
reward, kesempatan berkembang, waktu yang fleksibel, budaya organisasi, dan kondisi kerja (Oktariani dkk., 2017; Griffeth dkk., 2000 dalam Hindiarto, 2017), sehingga perlu untuk dilihat pengaruhnya terhadap intensi job hopping pada karyawan kalangan generasi milenial sehingga nantinya dapat menjadi perhatian bagi perusahaan. Selain itu, dalam penelitian yang dilakukan oleh Nastiti (2016) menyatakan bahwa tingkat kepuasan kerja para karyawan dengan rentan usia kurang dari 25 tahun sampai 45 tahun ada pada kategori tinggi, yang artinya sudah puas dengan pekerjaannya, tetapi fakta menyatakan bahwa karyawan yang berpindah-pindah perusahaan terus ada dan bahkan meningkat.

Sedangkan pemilihan grit untuk dilihat pengaruhnya terhadap intensi job hopping karena terdapat penelitian yang dilakukan oleh Tiara \& Rostiana (2018) menemukan bahwa karyawan generasi milenial memiliki tingkat grit yang sudah cukup tinggi, tetapi mengapa masih banyak fakta yang menyatakan bahwa para karyawan generasi milenial memiliki intensi berpindah-pindah pekerjaan yang tinggi.

\section{Intensi Job Hopping}

Pranaya (2014) menyebutkan job hopping sebagai suatu pola berganti-ganti perusahaan yang dilakukan atas kemauan pekerja itu sendiri dan bukan suatu paksaan dari perusahaan tersebut ataupun alasan lain seperti pemutusan hubunan kerja atau kebangkrutan perusahaan. Pola berganti-ganti perusahaan ini biasanya terjadi satu atau dua tahun dari awal masa kerjanya. Peneliti lain juga menyampaikan definisi serupa yang mana mendefinikan job hopping sebagai pekerja yang sering berganti-ganti pekerjaan dalam waktu singkat (Yuen, 2016).

Secara konsep, job hopping dapat dianggap sebagai voluntary turnover karena seorang pekerja memilih untuk meninggalkan perusahaan dalam waktu yang singkat berdasarkan keinginannya sendiri. Tetapi tidak semua voluntary turnover dapat dianggap sebagai job hopping. Hal ini karena fokus dari job hopping sendiri adalah pekerja yang berpindah-pindah secara sukarela walaupun baru menetap di suatu perusahaan dalam waktu yang singkat. Sehingga dalam memutuskan bahwa perilaku turnover merupakan job hopping harus terlebih dahulu mempertimbangkan waktu atau lamanya seseorang bekerja di perusahaan tersebut (Yuen, 2016).

Sedangkan intensi didefinisikan sebagai niat untuk melakukan sesuatu dan terus melakukannya (Ramdhani, 2011). Dari penjelasan job hopping yang sudah dipaparkan, penelitian ini menggunakan definisi intensi job hopping sebagai berikut, yaitu merupakan suatu keinginan berganti-ganti perusahaan dalam kurun waktu yang singkat dengan kisaran waktu satu atau dua tahun atas kemauan pekerja itu sendiri atau dengan kata lain bukan merupakan paksaan dari perusahaan, seperti pemutusan hubungan kerja ataupun kebangkrutan perusahaan (Pranaya, 2014).

\section{Grit}

Duckworth dkk (2007) menyatakan bahwa grit merupakan sifat non kognitif seseorang. Grit dapat diartikan sebagai ketekunan, semangat atau gairah seseorang untuk mecapai suatu tujuan dalam jangka waktu yang panjang. Grit mengharuskan individu bekerja keras untuk menghadapi tantangan, mempertahankan upaya atau usaha yang sudah dilakukan dan minat dalam kurun waktu yang panjang meskipun terjadi kegagalan dan kesulitan dalam prosesnya (Duckworth, Peterson, Matthews, \& Kelly, 2007). Individu yang memiliki grit tinggi (The gritty person) menganggap bahwa proses mencapai suatu tujuan itu seperti maraton, tidak perlu terburu-buru dalam mencapainya yang terpenting adalah kegigihan dan konsistensinya. Kegagalan, kekecewaan dan kebosanan tidak menjadi halangan bagi mereka untuk terus bergerak maju. Sementara individu yang memiliki grit rendah cenderung akan langsung menyerah ataupun meninggalkan tujuan awalnya jika menghadapi berbagai halangan 
(Duckworth, Peterson, Matthews, \& Kelly, 2007). Grit terdiri dari dua dimensi, yaitu consistensy of interests dan perseverance of effort.

1. Consistensy of interests

Dimensi ini merujuk pada konsistensi seseorang untuk mencapai suatu tujuan. Dengan kata lain, individu yang selalu fokus pada tujuan awalnya dan tidak mudah untuk berpindah haluan, perhatian mereka tidak mudah untuk teralihkan dan dapat mempertahankan minat mereka dalam waktu yang lama (Duckworth, Peterson, Matthews, \& Kelly, 2007).

2. Perseverance of effort

Dimensi ini merujuk pada ketekunan seseorang dalam melakukan suatu usaha walaupun terdapat banyak hambatan dalam proses penyelesaiannya. Individu yang gigih dalam berusaha tidak akan mudah menyerah, tidak mudah putus asa, dapat mengatasi hambatan yang datang untuk mencapai tujuan awalnya (Duckworth, Peterson, Matthews, \& Kelly, 2007).

\section{Kepuasan Kerja}

Kepuasan kerja terbukti meningkatkan efiensi karyawan dalam kegiatan organisasi dan produktivitas mereka. Kepuasan kerja yang dikemukakan oleh Smith dkk. (1969 dalam Azash \& Thirupalu, 2017) , yang menyatakan bahwa kepuasan kerja merujuk pada suatu perasaan atau respon afektif ataupun respon emosi seseorang terhadap suatu situasi dalam pekerjaannya.

\section{Karyawan Generasi Milenial}

Generasi milenial merupakan kelompok individu yang lahir tahun 1980 hingga akhir tahun 2000 (Smith \& Nichols, 2015). Kaifi dkk (2012) menyatakan bahwa generasi milenial adalah generasi terbaru yang memasuki dunia kerja.

Generasi milenial saat ini banyak kita temui di perusahaan-perusahaan. Berdasarkan laporan milenial tahun 2019 oleh PT. Astra International, menyatakan bahwa pada tahun 2019 kaum milenial menyumbang 70\% dari 250.000 karyawan di perseroan (Deloitte Indonesia Perspectives, 2019). Banyaknya generasi milenial di dunia industri, maka semakin banyak pula juga stereotip dan studi yang menyatakan jika generasi milenial tidak memiliki tingkat loyalitas yang tinggi dan mementingkan diri sendiri sehingga mereka mudah untuk berpindah-pindah pekerjaan (Thompson \& Gregory, 2012 dalam Smith \& Nichols, 2015). Menurut Debashish \& Ray, karakteristik dari generasi milenial ialah mereka tidak keberatan berpindah-pindah pekerjaan dan kemungkinan besar tidak akan tinggal di perusahaan selama lebih dari dua tahun (Yuen, 2016).

Berdasarkan penjelasan mengenai intensi job hopping, grit, dan kepuasan kerja, penelitian ini menyusun hipotesis sebagai berikut:

H1: Terdapat pengaruh grit terhadap intensi job hopping pada karyawan generasi milenial.

H2: Terdapat pengaruh kepuasan kerja terhadap intensi job hopping pada karyawan generasi milenial.

H3: Terdapat perngaruh grit dan kepuasan kerja terhadap intensi job hopping pada karyawan generasi milenial.

\section{Desain Penelitian}

\section{MET ODE}

Pada penelitian ini menggunakan penelitian kuantitatif yang dapat digunakan untuk meneliti suatu populasi tertentu yang bertujuan untuk menjelaskan atau menguji hipotesis dalam penelitian (Sugiyono, 2017), dengan teknik pengumpulan data berupa kuesioner skala. Penelitian ini

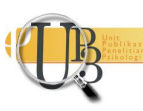


menggunakan metode kuantitatif eksplanatif karena ingin melihat penjelasan mengenai alasan sesuatu terjadi dan juga menguji hipotesis (Priyono, 2008). Jika dilihat dari dimensi waktu, penelitian kali ini termasuk ke dalam penelitian cross-sectional.

\section{Partisipan}

Partisipan pada penelitian ini merupakan karyawan full-time dari kalangan generasi milenial yang saat ini bekerja pada organisasi atau perusahaan kurang dari dua tahun. Penelitian ini menggunakan teknik non probability sampling jenis convenience sampling yang biasa juga dikenal sebagai haphazard sampling dan accidental sampling, dimana sampel bisa terpilih karena ada pada tempat, waktu, dan situasi yang tepat (Dornyei, 2007 dalam Etikan dkk., 2016). Sebelum melanjutkan untuk mengisi kuesioner penelitian, partisipan terlebih dahulu diminta untuk mengisi informed consent.

Penelitian ini menggunakan sebanyak 82 partisipan $\left(M_{\text {usia }}=25,8 ; S D_{\text {usia }}=5,05 ; 57,3\right.$ persen laki-laki; 42,7 persen perempuan). Usia partisipan didominasi oleh partisipan dengan rentan usia 20-25 tahun (54,9\%), kemudian partisipan dengan pendidikan terakhir S1 lebih mendominasi (62\%).

\section{Pengukuran}

Dalam mengukur intensi job hopping menggunakan job hopping intention scale (JHI) yang sudah diadaptasi dan diuji reliabilitas dan validitasnya oleh Suryaratri \& Abadi (2018). Skala ini terdiri dari empat item yang disusun menggunakan skala likert dengan lima rentang respon 1 sampai 5 ("1"= sangat tidak menggambarkan diri saya hingga "5"= sangat menggambarkan diri saya). Dalam mengukur grit menggunakan skala grit yang disusun oleh Duckworth dkk (2007) yang telah diadaptasi dan diuji reliabilitas dan validitasnya oleh Oktaviana (2018). Skala ini terdiri dari 12 item yang disusun menggunakan skala likert dengan lima rentang respon 1 sampai 5 ("1"= sangat tidak menggambarkan diri saya hingga " 5 "= sangat menggambarkan diri saya). Dalam mengukur kepuasan kerja menggunakan skala kepuasan kerja disusun oleh Chen dkk (2004) yang telah diadaptasi dan diuji reliabilitas dan validitasnya oleh Nastiti (2016). Skala ini terdiri dari enam item yang disusun menggunakan skala likert dengan rentang jawaban 1 hingga 5 ("1"= sangat tidak puas sampai " $5 "=$ sangat puas).

Validitas alat ukur job hopping intention pada penelitian ini telah di uji oleh Suryaratri \& Abadi, (2018). Teknik yang digunakan untuk mengukur validitasnya ialah jenis content validity. Validitas alat ukur grit juga telah diuji oleh Oktaviana (2018) yang juga menggunakan teknik content validity. Selanjutnya, untuk validitas dari skala kepuasan kerja yang disusun oleh Chen dkk (2004) yang telah diadaptasi oleh Nastiti (2016) diuji menggunakan convergent validity dan discriminant validity yang diuji menggunakan Partial Least Square (PLS).

Reliabilitas juga sudah diukur menggunakan Cronbach's Alpha. Untuk mengukur grit penulis menggunakan skala grit dengan 12 item pernyataan, dengan reliabilitas yang baik $(\alpha=.807)$. Alat ukur Job Hopping Intention (JHI) yang digunakan pada penelitian ini juga telah diuji reliabilitasnya menggunakan analisis Cronbach's Alpha. Nilai cronbach's alpha untuk variabel job hopping intention sebesar .91. Selanjutnya, reliabilitas alat ukur kepuasan kerja yang digunakan pada penelitian ini telah diuji reliabilitasnya menggunakan analisis composite reliability. Memenuhi reliabel jika nilai Composite Reliability > 0.7 (Ghozali, 2015 dalam Nastiti, 2016). Nilai yang diperoleh untuk variabel kepuasan kerja sebesar .884, sehingga dapat dikatakan memenuhi syarat reliabilitas. 


\section{Analisis Data}

Uji asumsi yang dilakukan menunjukan bahwa sebaran data adalah normal dan linear. Uji multikolinearitas yang dilakukan menunjukan bahwa tidak terdapat korelasi atau hubungan antar variabel independen pada model regresi. Selanjutnya, uji heteroskedastisitas berdasarkan gambar scatter plots regression menunjukan bahwa tidak terdapat ketidaksamaan variance dari residual satu pengamatan ke pengamatan lainnya. Dengan begitu, data penelitian memenuhi semua asumsi dan selanjutnya dianalisis menggunakan analisis regresi linear sederhana dan regresi linear berganda. Dalam mengolah data tersebut digunakan software IBM SPSS 23.0 for MacBook.

\section{H A S I L P E N EL I T I A N}

Hasil analisis deskriptif menunjukan bahwa partisipan yang memiliki grit tinggi sebanyak 18 partisipan (21,95\%), dalam kategori sedang terdapat 54 partisipan $(65,85 \%)$, dan pada kategori rendah terdapat 10 partisipan $(12,19 \%)$. Untuk kategorisasi kepuasan kerja, terdapat 14 partisipan yang memiliki tingkat kepuasan kerja yang tinggi $(17,07 \%)$, dalam kategori sedang terdapat 60 partisipan $(73,17 \%)$, dan dalam kategori rendah terdapat 8 partisipan (9,76\%). Selanjutnya untuk kategorisasi intensi job hopping terdapat 18 partisipan memiliki tingkat intensi job hopping yang tinggi (21,95\%), dalam kategori sedang terdapat 60 partisipan $(73,17 \%)$, dan pada kategori rendah terdapat 4 partisipan $(4,88 \%)$.

Hasil analisis regresi linear sederhana antara grit terhadap intensi job hopping menunjukkan bahwa grit dapat menjelaskan intensi job hopping pada karyawan generasi milenial sebesar $10,2 \%(\mathrm{~F}(1,80)=9.046$; $\left.\mathrm{p}<0,05 ; \mathrm{R}^{2}=0,102\right)$. Grit secara signifikan berpengaruh dengan sifat negatif terhadap intensi job hopping pada karyawan generasi milenial $(\beta=-0,319 ; p<0,05)$.

Hasil analisis regresi linear sederhana antara kepuasan kerja terhadap intensi job hopping menunjukkan bahwa kepuasan kerja dapat menjelaskan intensi job hopping pada karyawan generasi milenial sebesar $14,1 \%$ ( F (1,80=13.084; $\left.<<0,05 ; R^{2}=0,141\right)$. Kepuasan kerja secara signifikan berpengaruh dengan sifat negatif terhadap intensi job hopping pada karyawan generasi milenial $(\beta=-0,375 ; p<0,05)$.

Selanjutnya, hasil analisis regresi linear berganda menunjukkan bahwa grit dan kepuasan kerja dapat menjelaskan 19,2\% dari variabel intensi job hopping pada karyawan generasi milenial $(\mathrm{F}(2,79)=9.387$; $\left.\mathrm{p}<0,05 ; \mathrm{R}^{2}=0,192\right)$. Grit secara signifikan berpengaruh terhadap intensi job hopping pada karyawan generasi milenial $(\beta=-0,235 ; p<0,05)$, begitu pula dengan kepuasan kerja yang juga yang memiliki pengaruh terhadap intensi job hopping pada karyawan generasi milenial $(\beta=-0,312 ; \mathrm{p}<0,05)$.

\section{I S K U S I}

Tujuan dari penelitian ini adalah untuk melihat pengaruh grit dan kepuasan kerja terhadap intensi job hopping pada karyawan generasi milenial. Berdasarkan analisis yang sudah dilakukan, ditemukan hasil yang menunjukkan bahwa grit memiliki pengaruh negatif yang signifikan terhadap intensi job hopping pada karyawan generasi milenial. Sumbangan pengaruh yang diberikan grit terhadap intensi job hopping pada karyawan generasi milenial sebanyak 10,2\% dan selebihnya dipengaruhi oleh faktor lain yang tidak ikut diteliti dalam penelitian ini.

Hasil dari penelitian ini juga dapat memperkuat teori dari grit yang diteliti oleh Duckworth dkk (2007) yang mengatakan bahwa kegagalan, kekecewaan dan kebosanan tidak menjadi halangan bagi mereka yang memiliki grit tinggi untuk terus bergerak maju mencapai tujuannya. Sementara individu yang memiliki grit rendah cenderung akan langsung menyerah ataupun meninggalkan pekerjaannya jika 
menghadapi berbagai halangan. Dalam hal ini, karyawan generasi milenial yang gritty (sebutan untuk orang dengan grit tinggi) tidak akan mudah menyerah dan pindah-pindah pekerjaan, mereka cenderung akan terus bergerak maju walaupun mengalami kesusahan dalam pekerjaannya. Hasil dari penelitian ini juga dapat mendukung penelitian terdahulu yang dilakukan oleh Duckworth dkk (2007) yang juga melakukan penelitian yang terkait hubungan grit dengan intensi seseorang berpindah-pindah pekerjaan. Hasilnya mengungkapkan bahwa jika seseorang yang memiliki grit tinggi, intensinya untuk berpindah pekerjaan akan cenderung rendah. Selain itu, penelitian yang dilakukan oleh Salsabilla (2018) juga sejalan dengan hasil penelitian ini, dimana ia menyatakan bahwa grit memiliki pengaruh terhadap intensi job hopping dan sifatnya negatif.

Selanjutnya, dari analisis regresi yang sudah dilakukan, ditemukan hasil yang memperlihatkan bahwa kepuasan kerja memiliki pengaruh yang signifikan terhadap intensi job hopping pada karyawan generasi milenial, dengan sumbangan pengaruh yang diberikan variabel kepuasan kerja terhadap intensi job hopping pada karyawan generasi milenial sebanyak 14,1\% dan selebihnya dipengaruhi oleh faktor lain yang tidak masuk dalam penelitian ini.

Hasil dari penelitian ini juga memperkuat hasil penelitian sebelumnya yang dilakukan oleh Feng \& Angeline (2010) yang menyatakan bahwa kepuasan kerja seseorang berpengaruh signifikan terhadap intensi job hopping. Seseorang akan cenderung untuk melakukan job hopping jika merasa tidak puas pada pekerjaannya, sebaliknya mereka akan menetap pada pekerjaannya jika mereka merasakan kepuasan kerja yang tinggi. Penelitian lain yang juga selajan dengan penelitian ini adalah milik Larasati \& Aryanto (2019) yang menyatakan bahwa kepuasan kerja menjadi salah satu prekdiktor terjadinya perilaku job hopping. Kepuasan kerja pada penelitian ini mencakup pekerjaan itu sendiri, pengawasan (supervisi), upah atau pay, kesempatan mendapatkan promosi dan kepuasan kerja secara keseluruhan. Menurut Queiri dkk (2015), ketidakpuasan atas gaji dan tunjangan merupakan salah satu faktor yang menyebabkan karyawan milenial sering kali berpindah pekerjaan. Hasil tersebut juga memperkuat bahwa karyawan yang tingkat kepuasannya tinggi akan pekerjaannya termasuk didalamnya adalah gaji yang mana juga diukur pada penelitian ini, akan cenderung memiliki intensi job hopping rendah.

Studi lain yang juga sejalan dengan penelitian ini adalah milik Hindiarto (2017) yang menunjukan bahwa kepuasan kerja memiliki pengaruh terhadap intensi turnover, yang mana salah satu bentuknya ialah job hopping. Seorang karyawan yang masuk dalam suatu organisasi atau perusahaan akan memiliki ekpetasi yang tinggi terhadap upah, reward, kesempatan berkembang, waktu yang fleksibel, budaya organisasi, dan kondisi kerja (Griffeth dkk, 2000 dalam Hindiarto, 2017). Saat nantinya jika ekspetasi karyawan tersebut tidak terpenuhi, maka akan sangat mungkin terjadi ketidakpuasan kerja atau kepuasan kerja yang rendah dan berujung meninggalkan tempat kerja (Griffeth dkk, 2000 dalam Hindiarto, 2017).

Terakhir, dari analisis regresi yang sudah dilakukan, ditemukan hasil yang menunjukan bahwa variabel grit dan variabel kepuasan kerja secara bersama-sama atau simultan memiliki pengaruh yang signifikan terhadap intensi job hopping pada karyawan generasi milenial. Dan kontribusi yang lebih besar ada pada kepuasan kerja dengan nilai koefisien sebesar -0,245.

\section{S I M P U L A N}

Berdasarkan hasil penelitian yang sudah dilakukan, kesimpulan akhirnya ialah sebagai berikut, grit memiliki pengaruh dengan sifat negatif yang signifikan terhadap intensi job hopping pada karyawan generasi milenial. Selanjutnya, ditemukan bahwa kepuasan kerja memiliki pengaruh dengan sifat negatif yang signifikan terhadap intensi job hopping pada karyawan generasi milenial. Grit dan kepuasan 
kerja secara bersama-sama memiliki pengaruh dengan sifat negatif yang signifikan terhadap intensi job hopping pada karyawan generasi milenial. Kontribusi pengaruh yang paling besar dari kedua variabel faktor tersebut terdapat pada kepuasan kerja.

Saran untuk penelitian berikutnya diharapkan dapat meneliti dan menjelaskan dinamika dari variabel lain selain grit dan kepuasan kerja yang juga sekiranya dapat memprediksi intensi job hopping, seperti kelelahan emosional dan dukungan dari organisasi. Diharapkan juga dapat melakukan penelitian menggunakan jumlah partisipan yang lebih besar agar dapat menambah kedalaman pengetahuan terkait intensi job hopping, grit, dan kepuasan kerja dan agar dapat lebih menggambarkan fenomena. Saran untuk perusahaan diharapkan untuk memperhatikan kesejahteraan karyawannya, baik dari segi gaji, kesempatan promosi dan lainnya agar intensi job hopping pada perusahaan dapat berkurang. Perusahaan juga diharapkan dapat lebih mempertimbangkan aspek grit dalam melakukan seleksi. Bisa dengan menggunakan skala grit dalam seleksi masuk perusahaan. Selanjutnya, saran untuk karyawan generasi milenial diharapkan untuk mengurangi kecenderungan perilaku job hopping karena perusahaan akan ragu untuk merekrut karyawan yang memiliki riwayat job hopping.

\section{U C A P A N T E R I MAKASIH}

Terima kasih penulis ucapkan kepada Tuhan Yang Maha Esa, keluarga, teman-teman, serta pihak yang juga sudah mendukung dan membantu penulis dalam proses penyelesaian penelitian.

\section{DEKLARASI POTENSI TERJADINYAKONFLIK KEPENTINGAN}

Bertha Permatasari dan Fajrianthi tidak bekerja, menjadi konsultan, memiliki saham, atau menerima dana dari perusahaan atau organisasi maupun yang mungkin akan mengambil untung dari diterbitkannya naskah ini.

\section{PUSTAKA ACUAN}

Azash, S., \& Thirupalu, N. (2017). Scale For Measuring Job Satisfaction- A Review of Literature. EPRA International Journal of Economic and Business Review , 5 (3), 115.

Chen, T. Y., Chang, P. L., \& Yeh, C. W. (2004). An investigation of career development programs, job satisfaction, professional development and productivity: the case of Taiwan. Human Resource Development International .

Deloitte Indonesia Perspectives. (2019, September). Millennials in Industry 4.0: A Gift or a Threat to Indonesian Human Resources?.

Duckworth, A. L., Peterson, C., Matthews, M. D., \& Kelly, D. R. (2007). Grit: Perseverance and Passion for Long-Term Goals . Journal of Personality and Social Psychology, 92 (6), 1087-1101.

Etikan, I., Musa, S. A., \& Alkassim, R. S. (2016). Comparison of Convenience Sampling and Purposive Sampling . American Journal of Theoretical and Applied Statistics.

Feng, W. C., \& Angeline, T. (2010). Turnover intention and job hopping behaviour of music teachers in Malaysia. African Journal of Business Management, 4 (4), 425-434. 
Hindiarto, F. (2017). Menguji Konsistensi Korelasi Job Satisfaction dengan Intensi Turnover: Studi Meta-Analisis. Buletin Psikologi , 25 (2), 99-113.

Kaifi, B. A., Nafei, W. A., Khanfar, N. M., \& Kaifi, M. M. (2012). A Multi-Generational Workforce: Managing and Understanding Millennials . International Journal of Business and Management , 7 (24).

Larasati, A., \& Aryanto, D. B. (2019). Job-Hopping and the Determinant Factors. Advances in Social Science, Education and Humanities Research , 395.

Nastiti, R. A. (2016). Pengaruh Leader Member Exchange Terhadap Turnover Intention yang Dimediasi Oleh Job Satisfaction, Distributive Justice Dan Procedural Justice Pada Karyawan The Grand Darmo Suite Hotel . Surabaya: Universitas Airlangga.

Ngantung, D. (2013, 09 27). Survei Membuktikan: 60 Persen Anak Muda Indonesia Suka Berpindah Tempat Kerja. Retrieved 09 01, 2020, from Tribun Lifestyle: https://www.tribunnews.com/lifestyle/2013/09/27/survei-membuktikan-60-persen-anakmuda-indonesia-suka-berpindah-tempat-kerja

Oktariani, D., Hubeis, A. V., \& Sukandar, D. (2017). Kepuasan Kerja Generasi X dan Generasi Y Terhadap Komitmen Kerja di Bank Mandiri Palembang. urnal Aplikasi Bisnis dan Manajemen , 3 (1).

Oktaviana, M. (2018). Pengaruh Self Efficacy Dan Perceived Social Support Terhadap Grit pada Mahasiswa Pascasarjana Multidisiplin. Surabaya: Universitas Airlangga.

Pranaya, D. (2014). Job-Hopping - An Analytical Review. International Journal of Research in Business Management, 2 (4), 67-72.

Priyono. (2008). Metode Penelitian Kuantitatif. Sidoarjo: Zifatama.

Queiri, A., Yusoff, W. F., \& Dwaikat, N. (2015). Explaining Generation-Y Employees' Turnover in Malaysian Context. Asian Social Science , 11 (10), 126-138.

Ramdhani, N. (2011). Penyusunan Alat Pengukur Berbasis Theory of Planned Behavior. Buletin Psikologi , 19 (2), 55-69.

Salsabilla, F. (2019). Pengaruh Grit Terhadap Intensi Job Hopping pada Pekerja Generasi Y. Surabaya: Universitas Airlangga.

Sandra, M. R. (2019). Pengaruh Modal Psikologi dan Kepuasan Kerja Terhadap Intensi Job Hopping Pada Pekerja Generasi Milenial. Skirpsi, Surabaya.

Smith, T. J., \& Nichols, T. (2015). Understanding the Millennial Generation . 15 (1).

Sugiyono. (2017). Metode Penelitian Kuantitatif, Kualitatif, dan R\&D (26 ed.). Bandung: Alfabeta.

Suryaratri, R. D., \& Abadi, M. A. (2018). Modal Psikologis Dan Intensi Job Hopping pada Pekerja Generasi Millenial . IKRAITH-HUMANIORA .

Tiara, S., \& Rostiana. (2018). Peran Kualitas Kehidupan Kerja Dan Grit Terhadap Keterikatan Kerja Pada Generasi Millenial Di Industri Perbankan . Jurnal Muara Ilmu Sosial, Humaniora, dan Seni , 2 (1), 342-349. 
Yuen, S. H. (2016). Examining The Generation Effects On Job-Hopping Intention By Applying The Theory Of Planned Behavior (TPB). Hong Kong: Lingnan University . 